\title{
Health Insurance for Universal Health Coverage in India: A Critical Analysis based on Coverage, Distribution and Predictors from National Family Health Survey - 4 Data
}

\author{
Vikash R Keshri ( $\nabla$ vrkeshri@gmail.com ) \\ Centre for Health Policy, Asian Development Research Institute https://orcid.org/0000-0001-6668-0107
}

Saswata Ghosh

Centre for Health Policy, Asian Development Research Institute https://orcid.org/0000-0001-9337-683X

\section{Research article}

Keywords: Health Insurance, Universal Health Coverage, India, Ayushman Bharat, Pradhan Mantri Jan Arogya Yojana, National Family Health Survey

Posted Date: October 28th, 2019

DOI: https://doi.org/10.21203/rs.2.16513/v1

License: (c) (i) This work is licensed under a Creative Commons Attribution 4.0 International License. Read Full License 


\section{Abstract}

Background: The movement for Universal Health Coverage (UHC) is gaining momentum. Health insurance is emerging as one of the favoured means to finance healthcare. The union government of India also started a health insurance scheme in 2018 in the spirit to leap towards UHC. Therefore, this study was carried out with the following objectives. To understand the coverage, distribution, and predictors of health insurance coverage in India. To examine the role of Pradhan Mantri Jan Arogya Yojana (PM-JAY) towards the goal of UHC in India.

Methods: We analyzed unit-level data from the fourth round of National Family Health Survey (NFHS-4) to understand the coverage, distribution and predictors of health insurance. We categorized the health insurance schemes into four major categories based on standard categorization. The descriptive and bivariate analysis was conducted to understand the coverage and distribution and logit regression analysis was carried out to understand the predictors.

Results: The overall health insurance coverage in India was around $25 \%$ out of which $22 \%$ is mandatory health insurance. Less than $2 \%$ of households reported having any voluntary health insurance. Household wealth and education of the head of households were found to be directly proportional to health insurance coverage. Overall, there was very wide inter-state and inter-class variation in health insurance coverage, which reflect a major void in the existing programmes.

Conclusions: To achieve UHC in India, a definite policy direction is needed to protect those groups of citizens, who either not covered or are only partially covered from health insurance scheme. Either the PM-JAY scheme should be expanded for the larger population or an alternative health financing model is to be explored to expand the population coverage. Key-words: Health Insurance, Universal Health Coverage, India, Ayushman Bharat, Pradhan Mantri Jan Arogya Yojana, National Family Health Survey.

\section{Background}

The Universal Health Coverage (UHC) movement gained momentum during the last decade, especially after the world health report on this theme was published in 2010. ${ }^{1}$ The United Nations (UN) adopted a formal resolution on UHC in $2012 .^{2}$ According to World Health Organization (WHO), UHC means 'all people and communities can use the promotive, preventive, curative, rehabilitative and palliative health services they need, of sufficient quality to be effective, while also ensuring that the use of these services does not expose the user to financial hardship'. ${ }^{3}$ The inclusion of UHC as one of the targets of Goal-3 of Sustainable Development Goals (SDG) provided additional impetus to this movement. ${ }^{4}$ However, the debate and dilemma around the best way of financing for UHC continued. Despite this, the publicly financed health insurance has received evidently higher priority as a means to achieve UHC by many low and middle-income countries (LMICs).

'Health insurance' in a narrow sense can be defined as 'an individual or group purchasing health coverage in advance by paying a fee called premium'. In a broader sense, it can be defined as 'an arrangement that helps to defer, delay, reduce or altogether avoid paying for health care incurred by individuals or households'. ${ }^{5}$ The history of health insurance in highincome countries like Germany dates back to the nineteenth century. ${ }^{6}$ Over a period of time, varying models of health insurance were used in developed countries with variable results. The introduction of publicly financed health insurance in LMICs in African content is much recent. ${ }^{7}$ The new and emerging group of countries under BRICS (Brazil, Russia, India, China and South Africa) forum have also introduced diverse types of health insurance schemes in the last two decades. ${ }^{8}$ Asian countries like, Japan is one of the leading examples of UHC through the insurance model. ${ }^{9}$ Thailand is often cited as an example of a success story for UHC in south-east Asia through multiple ways of health financing. ${ }^{10}$

The history of health insurance in India dates back to more than 60 years ago. The two central government schemes, Employees' State Insurance Scheme (ESIS) and the Central Government Health Scheme (CGHS) were initiated in 1952 and 1954 respectively. These schemes catered to a very small proportion of the overall population of India. After liberalization and opening of foreign direct investment in the health insurance sector, the demand for health insurance started rising. ${ }^{11}$ The 
Rashtriya Swasthya Bima Yojana (RSBY) started in 2008 can be considered as a major turning point in the history of health insurance in India. By 2017, a state-specific health insurance scheme was already in place in 17 states and 4 Union Territories (UTs) (Figure 1 and Table 1). All these factors led to a movement of health insurance in the country which finally culminated in the unveiling of a mammoth health insurance scheme under the flagship 'Ayushman Bharat' (long live India) programme by Union Government of India (Gol). ${ }^{12}$ The health insurance scheme which is named as Pradhan Mantri Jan Arogya Yojana (PM-JAY) aims to cover approximately 107 million households and approximately 500 million Indians. This population coverage is around $40 \%$ of the total population of the country. The PM-JAY scheme is widely claimed to be the largest health insurance scheme in the world and as a step towards UHC in India (Government of India 2018). ${ }^{13}$ Therefore, in this study, we have analysed the secondary data from a nationally representative survey with the following specific objectives:

- To understand the coverage, distribution, and predictors of health insurance coverage in India.

- To examine the role of Pradhan Mantri Jan Arogya Yojana towards the goal of universal health coverage in India.

\section{Methods}

For this study, we used data from the fourth round of the National Family Health Survey (NFHS-4) conducted in the year 2015-16. The NFHS is a large-scale, periodic survey conducted in a nationally representative sample of households across India by the International Institute of Population Studies (IIPS) and ICF International, USA on behalf of the Ministry of Health and Family Welfare (MoHFW), Gol. In the household questionnaire of NFHS-4, questions on any member of the household being covered by any health insurance or scheme and the specific type of health insurance/scheme were included. A total of 601,509 households were interviewed. We analyzed unit-level data from the household survey component of NFHS -4 to understand the coverage, distribution, and predictors of health insurance in India. ${ }^{14}$

We categorized the health insurance schemes into four major categories as per the WHO classifications (WHO 2003)::5

Mandatory health insurance schemes: publicly financed health insurance scheme. This includes the ESIS, CGHS, RSBY and State Government Health Insurance Schemes.

Community-based health insurance ( $C B H I)$ : health insurance scheme run by population group usually supported by a civil society organization, which includes community health insurance programme.

Voluntary health insurance schemes: privately purchased commercial health insurance and other schemes

Employer-based health insurance schemes: medical insurance or reimbursement provided by employers.

Descriptive and bivariate analyses were conducted to understand the coverage and distribution of health insurance. Statewise coverage for all four types of health insurance was estimated. Distribution of health insurance coverage among different socio-demographic and socio-economic categories was analysed. Separate logit regression analyses were carried out to understand the predictors of health insurance at all India level. A p-value of $<0.05$ was considered significant. STATA version 15.0 (StataCorp, USA) was used for statistical analysis.

We have analysed data from a publicly available database. Therefore, this study is exempted from ethical review as per the Indian Council for Medical Research (ICMR) guideline on bio-medical and health research involving human subject published in $2017 .^{15}$

\section{Results}

\section{Health insurance coverage across India and Its States}


The overall health insurance coverage in India was around $25 \%$ out of which $22 \%$ was mandatory health insurance. Figure 2 shows the coverage of health insurance scheme in all 29 states of India. Andhra Pradesh (including Telangana) and Chhattisgarh have the highest coverage of health insurance, which stands at $74.5 \%$ and $68.4 \%$ respectively. Majority of the households in Tamil Nadu, Arunachal Pradesh, and Tripura were covered by health insurance. More than $30 \%$ of households were covered by health insurance in Kerala, Odisha, Mizoram, Meghalaya, West Bengal, and Sikkim. In Karnataka, Himachal Pradesh, Gujarat, and Punjab at least two out of every ten households were covered. Health insurance coverage in some of the largest states in India was very low. Two most populous states, viz., Uttar Pradesh and Maharashtra have very limited health insurance coverage of $6.1 \%$ and $15 \%$ respectively. Even the national capital territory of Delhi also has low insurance coverage of 15.5\%. Most of the states in Empowered Action Group (EAG) and Assam have low health insurance coverage $(<20 \%)$. Mandatory health insurance has been the most common type of health insurance across all the states. The coverage of $\mathrm{CBHI}$ was only $0.14 \%$ for overall India. None of the states has more than $1 \%$ coverage of $\mathrm{CBHI}$. The proportion of voluntary health insurance was highest in Maharashtra (5.8\%) followed by Kerala (5.7\%) and Delhi (5.5\%). The coverage of voluntary health insurance was more than $4 \%$ in the other three states, namely, Gujarat, Odisha, and Haryana. Employer-based health insurance coverage was also very low $(0.83 \%)$ at the national level. Only five states, viz., Tamil Nadu, Sikkim, Himachal Pradesh, Gujarat, and Goa have more than $2 \%$ coverage of employer-based health insurance (Figure 2).

\section{Socio-demographic characteristics of households and health insurance coverage}

Table 2 shows the coverage of health insurance schemes according to socio-demographic characteristics of households. The overall health insurance coverage was highest among the households with age of head of household between 46 to 65 years. Education of the head of household and health insurance coverage was found to be positively associated. The coverage of health insurance was found to be higher in accordance with the educational attainment of the household head. The difference in coverage between nuclear and non-nuclear households was not much.

Scheduled Castes (SC) and Scheduled Tribes (ST) households have higher coverage than other backward class (OBC) and other caste households mainly due to higher coverage of mandatory health insurance. However, coverage of voluntary and employer-based health insurance was lower among these groups. Hindu households have higher coverage than Muslims and other religions. Health insurance coverage was found to be higher among rural households as compared to their urban counterparts. But, the coverage of voluntary and employer-based health insurance was higher among urban households (Table 1).

\section{Socio-economic status of households and health insurance coverage}

The coverage of health insurance was almost directly associated with household wealth. Households falling under top three wealth quantile (richest, richer and middle-class) have higher health insurance coverage than those falling under lower two wealth quantile (poorer and poorest) households. More households from the urban, affluent and educated group were covered by any health insurance as compared to other groups. But the households in Below Poverty Line (BPL) category have $14 \%$ higher coverage as compared to non-BPL households. Similarly, households with a bank account have much higher coverage of health insurance. The households who preferred public health facilities for seeking treatment have better health insurance coverage (Figure 3).

\section{Predictors of household health insurance coverage}

We used logit regression analyses to understand the predictors of health insurance coverage in India. It was observed that the odds of being covered by any health insurance were significantly higher among the households where the age of head of the household was between 46 to 65 years followed by elderly (>65 years) households. Average marginal effect (AME) also suggests that the likelihood of having any health insurance was the highest among this group. Non-nuclear households have 
a higher likelihood of having health insurance as compared to nuclear families. The odds of having any health insurance was the highest among households, where the head of the households completed more than the secondary level of education. Households with an educated head of household significantly increased the odds of having any health insurance. Households belonging to the $\mathrm{OBC}$ and other castes, and Muslim and other religions have significantly lower odds of being covered as compared to SC/ST households. Possession of a bank account by household increased the likelihood of having health insurance by $9.2 \%$. Odds and the likelihood of having health insurance increased significantly with increasing wealth quantile of households. Rural households also have significantly higher odds of having health insurance. The gap in the likelihood of having health insurance between rural and urban households was found to be 3.4\% (Table 2).

\section{Discussion}

Our analysis shows some very interesting facts about health insurance coverage and its predictors in India. The results highlight the wide inter-state variation in health insurance coverage and socio-demographic and economic correlates of such variations. Overall, we found that at least one member of around one-quarter (25\%) of households in India is covered by any health insurance or scheme. This estimate is much higher than all previous estimates. A similar analysis using data from the third round of NFHS (NFHS-3) conducted in 2005-06 and third round of District Level Household Survey (DLHS-3) conducted in 2007-08 show that only about five per cent households were covered by any health insurance. ${ }^{16} \mathrm{~A}$ World Bank report in 2012 estimated the household coverage of any health insurance to be around $25 \%$ in India. ${ }^{17}$ We noted an inter-state variation in coverage ranging from around 75\% in Andhra Pradesh (including Telangana) to 6\% in Uttar Pradesh. In 2005-06, the inter-state variation in coverage was narrower with a range of around $11 \%$ in Karnataka to $1 \%$ in Bihar. ${ }^{16}$ It is evident that during the last two decade, the overall health insurance coverage increased dramatically and the inter-state variation widened.

We also observed a pattern in health insurance coverage by socio-demographic and economic categories of households. The households headed by the middle-aged person had a higher probability of coverage as compared to those with younger or elderly households. Education of the head of the household was significantly associated with higher coverage. The probability of having health insurance was higher among SC/ST caste group than other castes. The higher probability among $\mathrm{SC} / \mathrm{ST}$ was probably due to the nearly universal inclusion of this group by mandatory health insurance schemes.

There is plenty of evidence suggesting that the publicly financed health insurance scheme in LMICs results in no significant improvement in financial risk protection for poor households. Available evidence from India also suggests similar trends. ${ }^{18-}$

${ }^{20}$ Although the evidence also suggests a high positive spillover effect of health insurance on utilization of health care. ${ }^{21}$ There is plenty of evidence suggesting a positive impact of RSBY in improving utilization of health services but at the same time not in ensuring the financial risk protection. ${ }^{18-20}$ Therefore, it can be argued that the increased utilization of health care by insured households led to higher demand for health insurance but with limited impact on the reduction of financial risk.

Can the PM-JAY health insurance scheme be a definitive step towards UHC? Now, we are critically evaluating this based on the results of this study. The scheme aims to cover almost $40 \%$ of the country's population. The poor and deprived rural households and pre-identified occupational category of urban households are the targeted beneficiaries of the scheme. The benefits package includes hospitalization coverage for availing secondary and tertiary care services for an amount up to 500,000 Rupees per family per year. Around 1350 medical and surgical services including day-care, diagnostics and medicines are included in the package. ${ }^{13}$

Our estimates show that at least one member of around $25 \%$ of households is already covered by health insurance. As many as eight states already have more than $40 \%$ population coverage. In some of the states, the majority of the population is covered. The target group of PM-JAY is also the same group of the population who were already covered by any mandatory health insurance scheme. So, basically, the PM-JAY can increase the coverage of health insurance only in some states where it is currently low. The target population of PM-JAY effectively leave behind a larger section of middle-class Indians. Our analysis clearly indicates that middle and even richer and richest group of households do not have significantly higher 
coverage of health insurance. In states like Bihar and Uttar Pradesh, the poorest and poorer group have higher coverage than the middle and richer section. Similarly, the vulnerable group such as elderly households having low health insurance coverage are also left out. In the economically backward states of India, where the cut-off level for wealth classification is low, the urban, affluent and educated class are also not adequately covered by health insurance. These groups are also effectively omitted from PM-JAY scheme.

The second major objective of the PM-JAY is to reduce out of pocket expenditure (OOPE) and mitigate the risk of catastrophic health expenditure for the poor and vulnerable. As per available evidence, the proportion of OOP on secondary and tertiary care amounts to nearly one-third of total OOPE. ${ }^{22}$ A national-level estimate also observed no significant effect of health insurance on OOPE, the probability of catastrophic expenditure and impoverishment caused by health expenditure. ${ }^{23}$ The PMJAY does not have provision for primary or outpatient services. Based on available evidence, it can be argued that PM-JAY cannot reduce OOPE. Although it can play some role in the reduction of catastrophic health expenditure due to sudden hospitalization. The Health and Wellness Centre (HWC) which is the primary care component of Ayushman Bharat scheme also has its own set of challenges. ${ }^{24}$ There is an obvious incongruence between the allocated resources and stated objectives of HWC. In the absence of availability of comprehensive primary health care services and robust gatekeeping mechanism, the effectiveness of PM-JAY can be severely compromised. All the factors mentioned above will effectively be an unadorned bottleneck to the spirit of UHC in India.

\section{Conclusions}

It is evident that health insurance has become one of the main tools for ensuring financial risk protection to poor and vulnerable in India. Undoubtedly, PM-JAY is one of the most definitive steps in this direction. But the scheme effectively leaves behind a significant proportion of the population. This situation is further complicated by the rising cost of care for those not insured. Therefore, we recommend that a definite policy action must be taken to provide financial risk protection to those not covered by any scheme. The future policy should adopt a multi-pronged approach to include maximum possible beneficiaries in health insurance scheme with all benefits package. The possible approach towards universalization should include innovative solutions, such as: encouraging the citizen to enrol, an incentive for enrolling (i.e. tax benefit, bonus) or conditionally mandating enrolment in a voluntary health insurance scheme. Other options can be mandating or incentivizing employer-based schemes. The government should also explore options to provide premium-based health insurance to those who are currently not covered by any scheme. The regulation of insurance and health care providers are equally important determinants of future success for such schemes. More importantly, investments and efforts to strengthen comprehensive primary health care through the public health care delivery system should continue to be a high priority. All such combined efforts can definitely lead India towards UHC in future.

\section{List Of Abbreviation}

UHC - Universal Health Coverage

PM-JAY - Pradhan Mantri Jan Arogya Yojana

NFHS -4 - National Family Health Survey - 4

UN - United Nations

WHO - World Health Organization

SDG - Sustainable Development Goals

LMICs - Low- and Middle-Income Countries

BRICS - Brazil, Russia, India, China, South Africa 
CGHS - Central Government Health Scheme

ESIS - Employee State Insurance Scheme

RSBY - Rashtriya Swasthya Bima Yojana

UTs - Union Territories

Gol - Government of India

IIPS - International Institute of Population Studies

MoHFW - Ministry of Health and Family Welfare

CBHI - Community Based Health Insurance

ICMR - Indian Council of Medical Research

EAG - Empowered Action Group

SC - Schedule Caste

ST - Schedule Tribe

OBC - Other Backward Caste

BPL - Below Poverty Line

AME - Average Marginal Effect

DLHS - District Level Household Survey

OOPE - Out of Pocket Expenditure

HWC - Health and Wellness Centre

\section{References}

1. World Health Organization. Health System Financing: The Path to Universal Health Coverage. Geneva: WHO;2010. Available from: https://www.who.int/whr/2010/10_summary_en.pdf?ua=1 Accessed 10 June 2019

2. United Nations. Resolution Adopted by General Assembly on 12 December 2012. Available from: https://www.un.org/en/ga/search/view_doc.asp?symbol=A/RES/67/81 Accessed 10 June 2019

3. int [Internet]. Geneva: World Health Organization. c2019 [Cited 2019 June 10]. Available from: https://www.who.int/health_financing/universal_coverage_definition/en/_Accessed 10 June 2019

4. United Nations. Global indicator framework for the Sustainable Development Goals and targets of the 2030 Agenda for Sustainable Development. New York. Available from: https://unstats.un.org/sdgs/indicators/indicators-list/. Accessed 10 June 2019

5. World Health Organization. Social Health Insurance: Report of Regional Expert Group Meeting. New Delhi. 13-15 March, 2003. Available from: http://apps.searo.who.int/pds_docs/B3457.pdf. Accessed 10 June 2019

6. Busse R, Blummel M. Germany: health system review. Health Syst Transit. 2014; 16(2):1-296. Available from: http://www.euro.who.int/_data/assets/pdf_file/0008/255932/HiT-Germany.pdf?ua=1 Accessed 10 June 2019 
7. Africa Amu' Amu H, Dickson KS, Kumi-Kyereme A, Darteh EKM. Understanding variations in health insurance coverage in Ghana, Kenya, Nigeria, and Tanzania: Evidence from demographic and health surveys. PLoS ONE 13(8): e0201833.

8. Marten R, McIntyre D, Travassos C, Shishkin S, Longde W, Reddy S, Vega J. An assessment of progress towards universal health coverage in Brazil, Russia, India, China, and South Africa (BRICS). Lancet 2014; 384: 2164-71.

9. Tatara K, Okamoto E. Japan Health System Review. Health Syst Transit. 2009;11(5):1-164. Available from: https://apps.who.int/iris/bitstream/handle/10665/259941/9789290226260-eng.pdf?sequence=1 Accessed 10 June 2019

10. World Health Organization. Regional Office for the Western Pacific and Asia Pacific Observatory on Health Systems and Policies. The Kingdom of Thailand: Health System Review. Health Syst Transit. 2015; 5 (5)

11. Public Health Foundation of India. A Critical Assessment of the Existing Health Insurance Models in India: A Report Submitted to Planning Commission. New Delhi. 31 January, 2011. Available from: http://planningcommission.nic.in/reports/sereport/ser/ser_heal1305.pdf Accessed June 10, 2019.

12. nic.in [Internet]. New Delhi: Government of India. c2019 [Cited June 10,2019] Ayushman Bharat for a new India -2022, announced. Available from: http://pib.nic.in/newsite/PrintRelease. aspx?relid=176049 Accessed June 10, 2019

13. gov.in [Internet]. New Delhi: Government of India. c2019 [Cited June 10,2019]. About Pradhan Mantri Jan Arogya Abhiyan. Available from: https://www.pmjay.gov.in/about-pmjay Accessed June 10,2019

14. International Institute for Population Sciences. National family health Survey (NFHS-4), 2015-16: India, Mumbai, 2017. Available from: http://rchiips.org/nfhs/NFHS4Reports/India.pdfAccessed June 10, 2018

15. Indian Council of Medical Research. National Ethical Guidelines for Biomedical and Health Research Involving Human Participants. New Delhi. 2017. Available from: https://www.icmr.nic.in/sites/default/files/guidelines/ICMR_Ethical_Guidelines_2017.pdf Accessed June 10, 2019

16. Shijith VP, Sekhar TV. Who Gets Health Insurance Coverage in India? New Findings from Nation-Wide Surveys. Proceedings of XXVII IUSSP International Population Conference. Busan, Republic of Korea Aug 26 -31, 2013. Available from: https://iussp.org/sites/default/files/event_call_for_papers/shijith_health\%20insurance.pdf Accessed June 10, 2019

17. Forgia GL, Nagpal S. 2012. Government-Sponsored Health Insurance in India: Are You Covered? Directions in Development. Washington, DC: World Bank. doi:10.1596/978-0-8213-9618-6. Available from: https://openknowledge.worldbank.org/bitstream/hadle/10986/11957/722380PUBOEPI008029020120Box367926B.pdf? sequence=1\&isAllowed $=y$ Accessed June 10, 2019

18. Devadasan N, Seshadri T, Trivedi M, Criel B. Promoting universal financial protection: evidence from the Rashtriya Swasthya Bima Yojana (RSBY) in Gujarat, India. Heal Res Policy Syst. 2013;11(1):1.

19. Karan A, Yip W, Mahal A. Social Science \& Medicine Extending health insurance to the poor in India: An impact evaluation of Rashtriya Swasthya Bima Yojana on out of pocket spending for healthcare. Soc Sci Med. 2017; 181:83-92.

20. Prinja S, Chauhan AS, Karan A, Kaur G, Kumar R. Impact of Publicly Financed Health Insurance Schemes on Healthcare Utilization and Financial Risk Protection in India: A Systematic Review. PloS ONE 12(2): e0170996.

21. Chatterjee $C$, Joshi R, Sood N, Boregowda P. Government health insurance and spatial peer effects: New evidence from India. Soc Sci Med.2018 Jan; 196:131-141

22. National Health Systems Resource Centre. National Health Accounts Estimates for India (2015-16).2018. New Delhi: Ministry of Health and Family Welfare, Government of India. Available from:

http://nhsrcindia.org/sites/default/files/NHA\%20Estimates\%20Report\%20-\%20November\%202018_0.pdf Accessed June 10, 2019

23. Ravi S, Ahluwalia R, Bergkvist S. Health and Morbidity in India (2004-2014). Brookings India Research Paper No. 092016. 2016. Available from: https://www.brookings.edu/wp-content/uploads/2016/12/201612_health-and-morbidity.pdf Accessed June 10, 2019 
24. Lahariya C. Ayushman Bharat Program and Universal Health Coverage in India. Indian Pedatr.2018 Jun 15;55 (6):495506.

\section{Tables}

Table 1: Evolution of state Health Insurance schemes in India

\begin{tabular}{|c|c|c|}
\hline Year & State & Scheme \\
\hline 2003 & Karnataka & $\begin{array}{l}\text { Yashaswi Health Insurance Scheme and Vajpayee Arogyashree Scheme in } \\
\text { 2009. }\end{array}$ \\
\hline 2007 & Andhra Pradesh & Arogyashree Scheme \\
\hline 2008 & Kerala & Comprehensive Health Insurance Scheme (CHIS) and CHIS Plus \\
\hline 2010 & Maharashtra & $\begin{array}{l}\text { Rajiv Gandhi Jeevandayee Aarogya Yojana and Mahatma Jyotiba Phule } \\
\text { Jeevandayee Aarogya Yojana since } 2017\end{array}$ \\
\hline 2012 & $\begin{array}{l}\text { Gujarat } \\
\text { Tamil Nadu } \\
\text { Meghalaya }\end{array}$ & $\begin{array}{l}\text { Mukhya Mantri Amrutam Yojana } \\
\text { Chief Minister Comprehensive Health Insurance Scheme and Chief } \\
\text { Minister's Kalainagar Health Insurance Scheme since } 2009 . \\
\text { Megha Health Insurance Scheme }\end{array}$ \\
\hline 2013 & $\begin{array}{l}\text { Chhattisgarh } \\
\text { Odisha } \\
\text { Dadra and Nagar } \\
\text { Haveli, Daman and Diu }\end{array}$ & $\begin{array}{l}\text { Mukhya Mantri Swasthya Bima Yojana } \\
\text { Biju Swasthya Kalyan Yojana } \\
\text { Sanjeevani Swasthya Bima Yojana }\end{array}$ \\
\hline 2014 & Arunachal Pradesh & $\begin{array}{l}\text { The Arunachal Pradesh Chief Minister's Universal Health Insurance } \\
\text { Scheme }\end{array}$ \\
\hline 2015 & $\begin{array}{l}\text { Andaman and Nicobar } \\
\text { Island } \\
\text { Punjab } \\
\text { Rajasthan }\end{array}$ & $\begin{array}{l}\text { Andaman and Nicobar Island Scheme for Health Insurance } \\
\text { Bhagat Puran Singh Health Insurance Scheme } \\
\text { Bhamashah Health Insurance Scheme }\end{array}$ \\
\hline 2016 & $\begin{array}{l}\text { Goa } \\
\text { Himachal Pradesh } \\
\text { Puducherry } \\
\text { Uttarakhand } \\
\text { Assam } \\
\text { West Bengal }\end{array}$ & $\begin{array}{l}\text { Deen Dayal Swasthya Seva Yojana } \\
\text { Mukhya Mantri State Health Care Scheme and Rashtriya Swasthya Bima } \\
\text { Yozna Plus (RSBY Plus) since } 2010 \\
\text { Puducherry Medical Relief Society Scheme } \\
\text { Mukhya Mantri Swasthya Bima Yojana } \\
\text { Atal Amrit Abhiyan } \\
\text { Swasthya Sathi }\end{array}$ \\
\hline
\end{tabular}

\# This is not a complete list of all health insurance schemes by the state governments in India. The source of information for all the schemes is official websites.

Table 2: Health Insurance coverage in India according to socio-demographic characteristics of households 


\begin{tabular}{|c|c|c|c|c|c|}
\hline & $\begin{array}{l}\text { Any Health } \\
\text { Insurance }\end{array}$ & $\begin{array}{l}\text { Mandatory } \\
\text { Health } \\
\text { Insurance }\end{array}$ & $\begin{array}{l}\text { Community-Based } \\
\text { Health Insurance }\end{array}$ & $\begin{array}{l}\text { Voluntary } \\
\text { Health } \\
\text { Insurance }\end{array}$ & $\begin{array}{l}\text { Employer-based } \\
\text { Health Insurance }\end{array}$ \\
\hline Overall Coverage & 25.06 & 22.24 & 0.14 & 1.85 & 0.83 \\
\hline \multicolumn{6}{|c|}{ Age of head of household (in years) } \\
\hline$<=25$ & 14.65 & 13.22 & 0.08 & 1 & 0.34 \\
\hline $26-45$ & 23.81 & 21.27 & 0.13 & 1.67 & 0.73 \\
\hline $46-65$ & 27.24 & 24.07 & 0.16 & 2.04 & 0.97 \\
\hline$>65$ & 25 & 21.94 & 0.13 & 2.08 & 0.85 \\
\hline \multicolumn{6}{|l|}{ Family Type } \\
\hline Nuclear & 24.86 & 22.2 & 0.14 & 1.68 & 0.84 \\
\hline Non-nuclear & 24.34 & 22.29 & 0.15 & 2.08 & 0.82 \\
\hline \multicolumn{6}{|c|}{ Education of head of household } \\
\hline $\begin{array}{l}\text { No education/ } \\
\text { semi-literate }\end{array}$ & 23.53 & 22.29 & 0.1 & 0.92 & 0.22 \\
\hline Primary & 27.34 & 25.55 & 0.12 & 1.33 & 0.35 \\
\hline Secondary & 24.35 & 21.31 & 0.15 & 1.98 & 0.91 \\
\hline Higher & 28.44 & 19.86 & 0.29 & 5.05 & 3.23 \\
\hline \multicolumn{6}{|c|}{ Caste of Head of Household } \\
\hline $\begin{array}{l}\text { Scheduled Caste } \\
\text { /Scheduled Tribe }\end{array}$ & 28.92 & 27.19 & 0.08 & 1.19 & 0.46 \\
\hline $\begin{array}{l}\text { Other Backward } \\
\text { Caste }\end{array}$ & 24.27 & 21.6 & 0.16 & 1.72 & 0.79 \\
\hline Others & 20.47 & 15.64 & 0.2 & 3.14 & 1.49 \\
\hline \multicolumn{6}{|c|}{ Religion of Head of Household } \\
\hline Hindu & 25.92 & 22.77 & 0.15 & 2.09 & 0.91 \\
\hline $\begin{array}{l}\text { Muslims and } \\
\text { others }\end{array}$ & 22.45 & 20.62 & 0.11 & 1.12 & 0.59 \\
\hline \multicolumn{6}{|l|}{ Place of Residence } \\
\hline Urban & 24.69 & 19.7 & 0.2 & 2.96 & 1.82 \\
\hline Rural & 25.24 & 23.47 & 0.11 & 1.3 & 0.35 \\
\hline
\end{tabular}

Table 3: Predictors of Health Insurance coverage in India 


\begin{tabular}{|c|c|c|c|}
\hline & \begin{tabular}{|l|} 
Odds Ratio \\
(95\% Confidence Interval) \\
\end{tabular} & $\begin{array}{c}\text { Adjusted Marginal Effect (AME) } \\
\text { (in \%) }\end{array}$ & p Value* \\
\hline \multicolumn{4}{|c|}{ Age of head of household (In Years) } \\
\hline$\frac{\leq 25}{26-45}$ & $\begin{array}{c}1.00 \\
1.36 \\
(129-144)\end{array}$ & $\begin{array}{c}9.79 \\
12.65\end{array}$ & 0.00 \\
\hline $46-65$ & $\begin{array}{c}(1.29-1.44) \\
(1.28-1.42)\end{array}$ & 12.51 & 0.00 \\
\hline$>65$ & $\begin{array}{c}1.14 \\
(1.07-1.22)\end{array}$ & 10.95 & 0.00 \\
\hline \multicolumn{4}{|l|}{ Household Type } \\
\hline Nuclear & 1.00 & 11.84 & \\
\hline Non-Nuclear & $\begin{array}{c}1.09 \\
(1.07-1.12)\end{array}$ & 12.71 & 0.00 \\
\hline \multicolumn{4}{|c|}{ Educational Status of head of household } \\
\hline Tlliterate / Semi-literate & 1.00 & 12.28 & \\
\hline Primary & $\begin{array}{c}1.03 \\
(1.00-1.07)\end{array}$ & 12.61 & 0.05 \\
\hline Secondary & $\begin{array}{c}0.99 \\
(0.97-1.02)\end{array}$ & 12.23 & 0.69 \\
\hline Higher & $\begin{array}{c}0.91 \\
(0.86-0.96)\end{array}$ & 11.36 & 0.001 \\
\hline \multicolumn{4}{|l|}{ Caste of Head of Household } \\
\hline Schedule Caste/Schedule Tribe & 1.00 & 13.98 & \\
\hline Other Backward Caste & $\begin{array}{c}0.80 \\
(0.78-0.82)\end{array}$ & 11.65 & 0.00 \\
\hline Others & $\begin{array}{c}0.80 \\
(0.77-0.83)\end{array}$ & 11.70 & 0.00 \\
\hline \multicolumn{4}{|l|}{ Religion } \\
\hline $\begin{array}{l}\text { Hindu } \\
\text { Muslim/Others }\end{array}$ & $\begin{array}{c}1.00 \\
1.00 \\
(0.98-1.04)\end{array}$ & $\frac{12.25}{12.33}$ & 0.63 \\
\hline \multicolumn{4}{|l|}{ Below Poverty Line Status } \\
\hline Above Poverty Line & 1.00 & 6.05 & \\
\hline Below Poverty Line & $\begin{array}{c}3.39 \\
(3.30-3.48)\end{array}$ & 17.23 & 0.00 \\
\hline \multicolumn{4}{|l|}{ Bank Account Status } \\
\hline No Bank Account & 1.00 & 9.08 & \\
\hline Having Bank Account & $\begin{array}{c}1.62 \\
(1.56-1.66)\end{array}$ & 13.56 & 0.00 \\
\hline \multicolumn{4}{|l|}{ Socio-Economic Status } \\
\hline Poorest & 1.00 & 12.43 & \\
\hline Poorer & $\begin{array}{c}0.99 \\
(0.96-1.02)\end{array}$ & 12.31 & 0.40 \\
\hline Middle & $\begin{array}{c}0.90 \\
(0.86-0.93)\end{array}$ & 11.37 & 0.00 \\
\hline Richer & $\begin{array}{c}0.76 \\
(0.72-0.80)\end{array}$ & 9.85 & 0.00 \\
\hline Richest & $\begin{array}{c}1.78 \\
(1.66-1.92)\end{array}$ & 19.39 & 0.00 \\
\hline \multicolumn{4}{|l|}{ Place of Residence } \\
\hline Urban & 1.00 & 11.26 & \\
\hline Rural & $\begin{array}{c}1.12 \\
(1.08-1.17)\end{array}$ & 12.39 & 0.00 \\
\hline
\end{tabular}

${ }^{*}$ p value $:<0.05$ - significant $<0.01$ - highly significant 


\section{Declarations}

\section{Ethics approval and consent to participate}

This study is based on analysis of data from a publicly available database. Therefore, this study is exempted from ethical review as per the Indian Council for Medical Research (ICMR), India guideline on bio-medical and health research involving human subject published in 2017.

\section{Consent for publication}

Not Applicable.

\section{Availability of data and materials}

The datasets generated and/or analysed during the current study are available in the Demographic and Health Survey (DHS) Program repository available from: https://www.dhsprogram.com/data/dataset/India_Standard-DHS_2015.cfm?flag=0

\section{Competing interests}

The authors declare that they have no competing interests

\section{Funding}

This study was funded by a grant from the Bill and Melinda Gates Foundation. The funding body was not involved in design of the study, data collection, analysis and interpretation of data or writing of manuscript.

\section{Authors' contributions}

VRK and SG conceptualized the study and its design. VRK carried out literature search, SG analysed the data. SG and VRK interpreted the data. VRK drafted the manuscript and SG provided his inputs in to it. Both authors read and approved the final manuscript.

\section{Acknowledgements}

Authors acknowledge the contribution of Dr Nutan Shashi Tigga for reviewing the manuscript prior to publication.

\section{Figures}




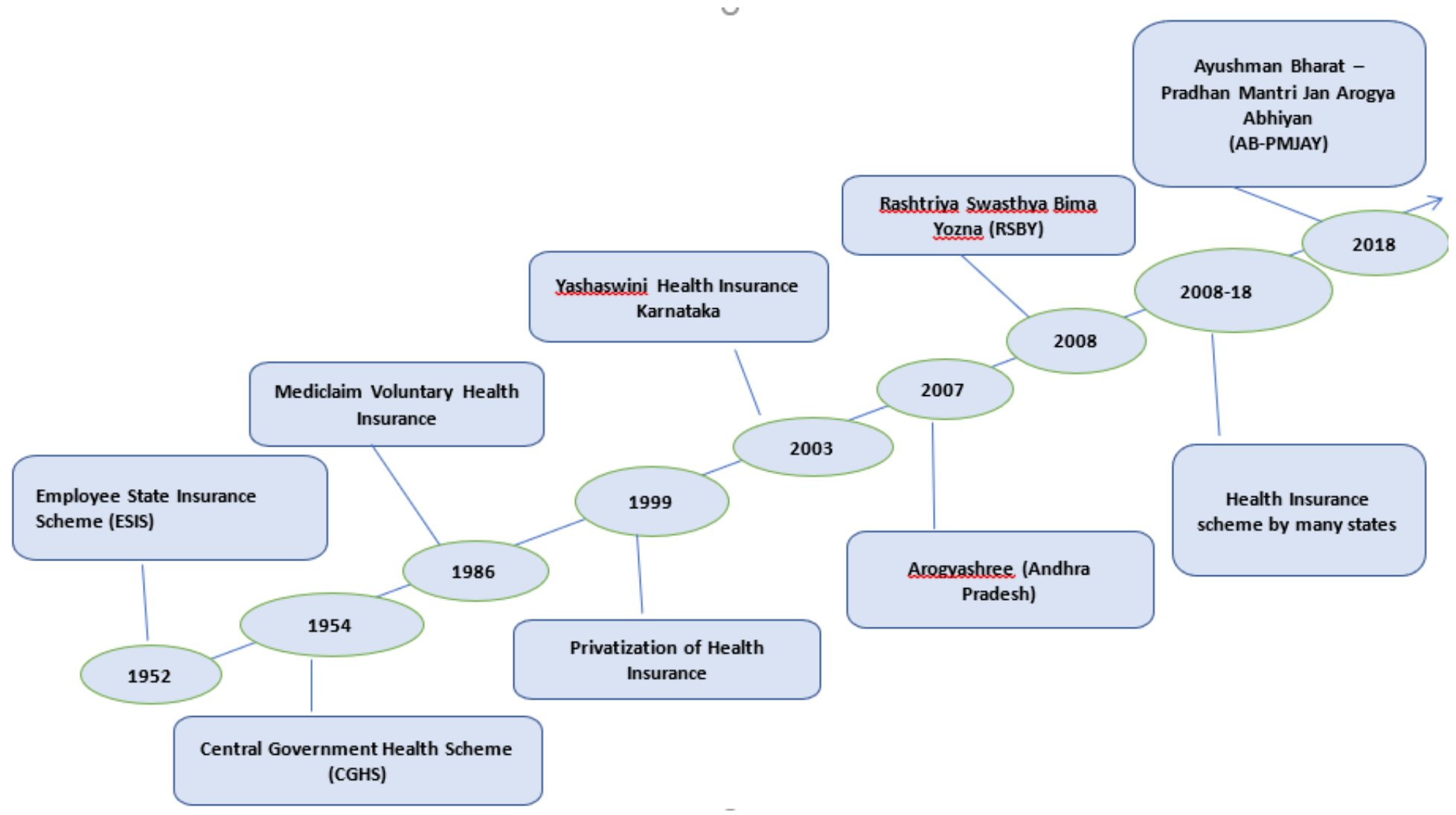

Figure 1

The historical evolution of Health Insurance schemes in India.

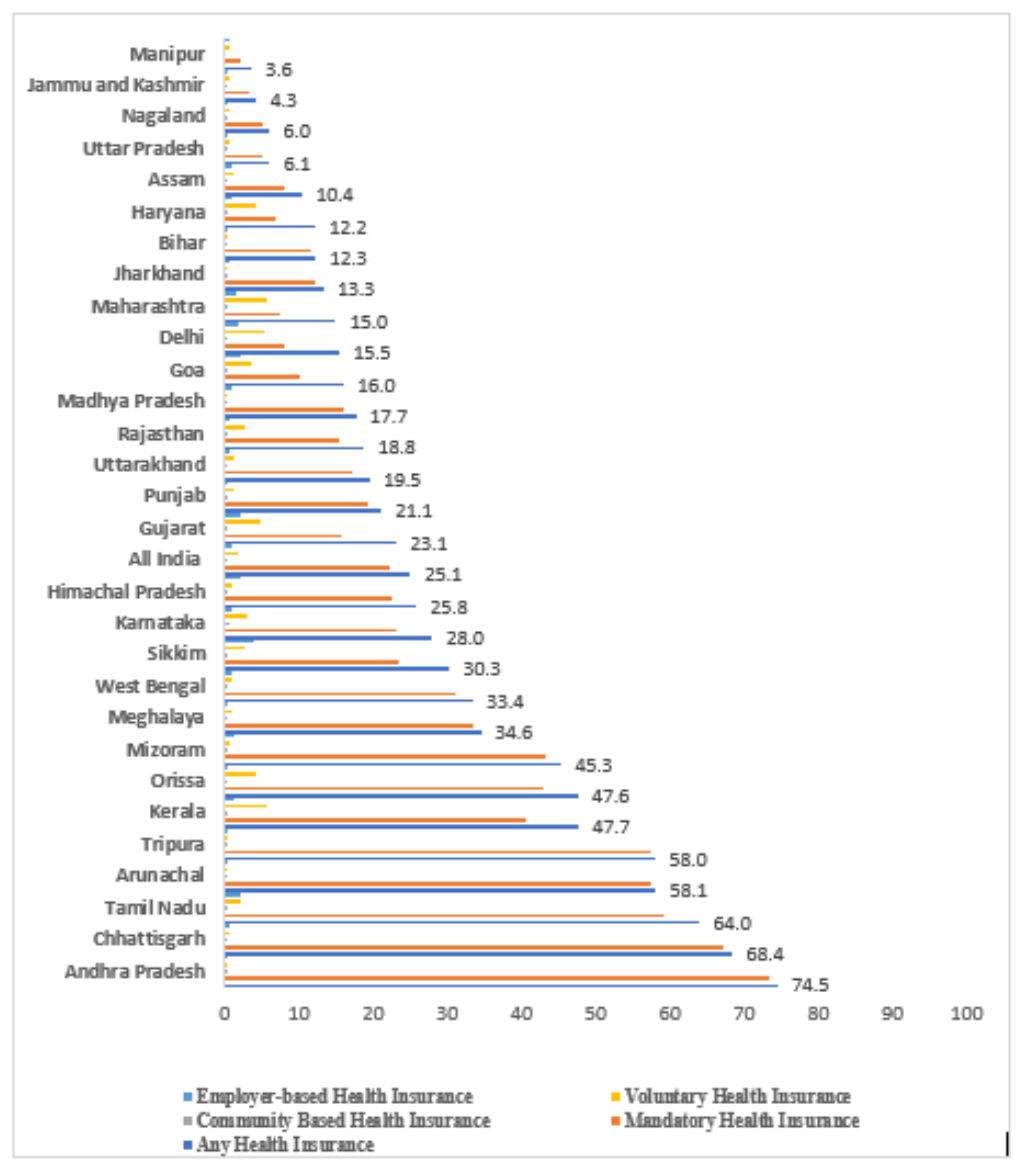




\section{Figure 2}

Inter-state variation in Health Insurance coverage in India

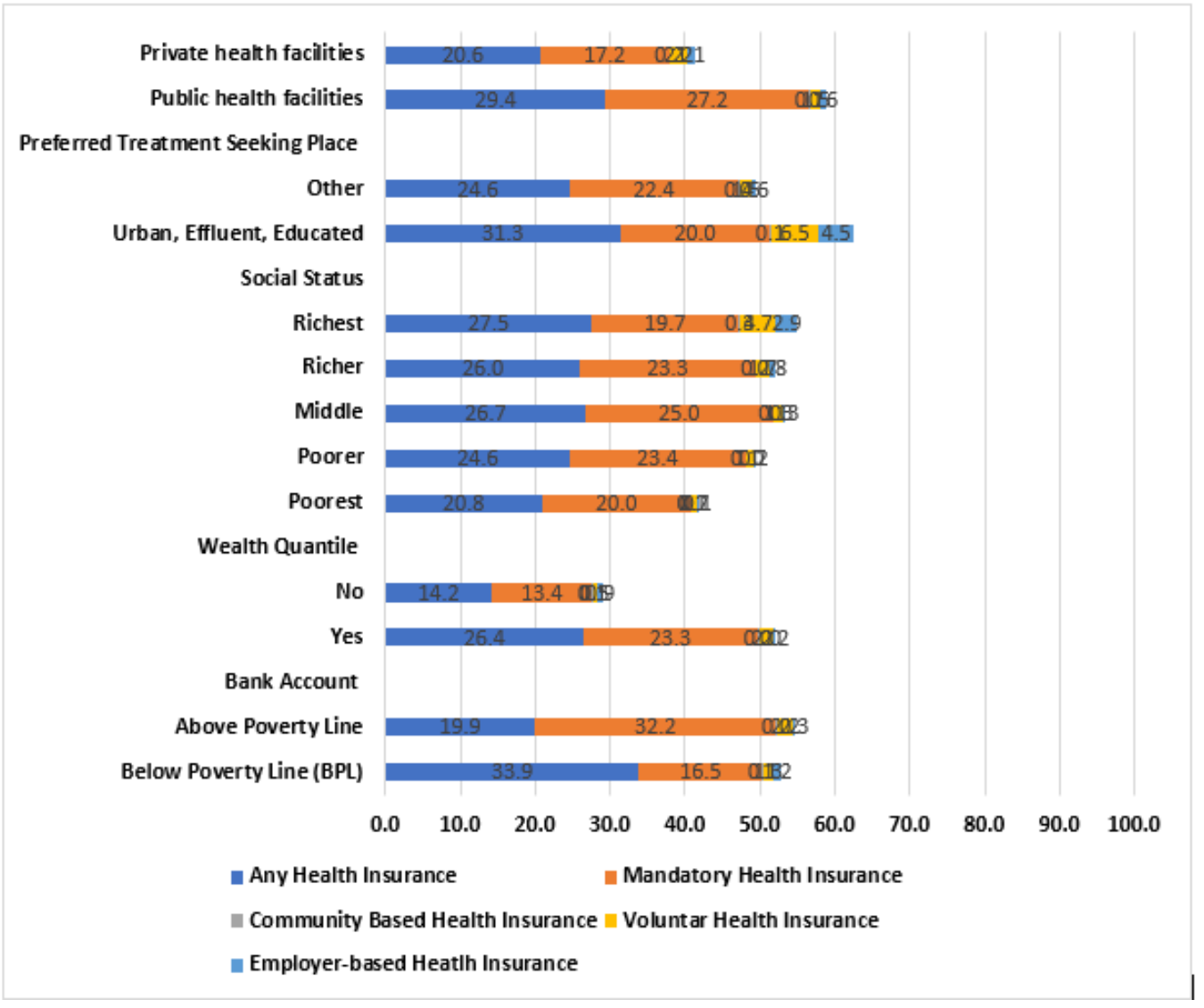

\section{Figure 3}

Socio-economic status of households and coverage of Health Insurance in India 